\title{
Participación, deliberación y excelencia (en la esfera pública y en la esfera privada). En torno a la filosofía política de John Stuart Mill

\author{
Participation, deliberation and excellence \\ (in the public and private spheres). \\ On Mill's Political Philosophy
}

\author{
Ana de Miguel Álvarez
}

Universidad Rey Juan Carlos

Resumen. John Stuart Mill es un autor que genera tanta fascinación y lealtad - por la asombrosa coherencia entre sus ideas, su vida y su práctica política- como indiferencia y paternalismo. En este último caso queda descalificado como un autor ecléctico, inclasificable, ni liberal ni socialista, ya lo había dicho Marx: «Mill, ese pequeño burgués bienpensante». Inmersos como estamos en las publicaciones que continúan celebrando el bicentenario de su nacimiento, es un buen momento para valorar por qué su figura y su obra están ganando en profundidad y actualidad con el tiempo. En este artículo nos centramos en su filosofía política, una de las partes menos estudiadas y cada vez más reivindicada. En concreto en sus planteamientos sobre la democracia participativa y deliberativa y la demanda de extender sus principios a la esfera privada y la económica.

Palabras clave: Democracia deliberativa, democracia participativa, principio de excelencia, cooperativismo, feminismo.
Abstract. John Stuart Mill is an author who generates fascination and loyalty in equal measure with indifference and paternalism. The former is due to the outstanding coherence between his ideas, his life and his political actions, while the latter has led to him being denounced as an author who is too eclectic and difficult to classify, being neither liberal or socialist. At present, we are witnessing a flood of publications in a celebration of the two-hundredth anniversary of Mill's birth. This is an appropriate moment to consider why Mill and his work continue to gain depth of meaning and relevance to the present. This article focuses on his political philosophy, one of the least studied aspects of his work, though increasingly valued. We examine his thoughts on participatory and deliberative democracy, in addition to his call for the extension of these principals to the private and economic sphere.

Key words: Deliberative democracy, participatory democracy, excellence, cooperatives, feminism. 


\section{Un apunte biográfico}

El joven Mill fue educado para ser un reformador social al servicio de la filosofía utilitarista, «la mayor felicidad del mayor número». Sometido a una estricta disciplina por su padre, el también filósofo James Mill, pronto se convirtió en una enciclopedia viviente y en una máquina racional de pensar (de pensar como su padre). Sin embargo, tras su primera depresión, con apenas veinte años, emergió un pensador independiente que, sin abandonar nunca del todo el utilitarismo y el radicalismo político, estaba decidido a elaborar sus propias preguntas y respuestas. Fue un pensador sumamente receptivo a las diferentes corrientes de pensamiento de su época. El fin de su filosofía fue conciliar las diferentes partes de verdad que a su juicio se encuentran en teoría antagónicas. En su Autobiografía relata con detalle este proceso de evolución personal e intelectual y el alcance de sus deudas intelectuales. Se trata de una autobiografía intelectual verdaderamente apasionante ${ }^{1}$.

La reforma social fue el centro de su vida y de su obra. Nunca dejó de militar en círculos de radicales y de publicar sus opiniones, tratando de intervenir en la formación de una opinión pública ilustrada. Su trabajo de por vida en una agencia gubernamental, la East Indian Company, le permitió conocer las dificultades de la gestión pública y, no menos importante, obtener un salario que le permitió ser siempre independiente del poder político. Una vez retirado aceptó presentarse a ocupar un escaño en el Parlamento. Tanto su peculiar campaña electoral como sus años de parlamentario ilustran una asombrosa coherencia entre sus ideas y su práctica política. Se negó a emplear dinero personal en la campaña y en los escasos mítines que dio, advirtió a los votantes del distrito de Westminster, de que no iría a su escaño a defender sus intereses, iría a defender el interés general. Tal y como sentenció un hombre del mundo político, con tal campaña ni el Todopoderoso podría salir elegido. Mill derrotó al candidato conservador. De sus años parlamentarios baste con señalar que el diputado se jugó su reputado prestigio presentando la primera petición al voto femenino ${ }^{2}$. Los comentarios que se escuchaban compadecían al «santón del racionalismo», al pobre ingenuo que se iba a cargar su carrera política». Tenían razón, se la cargó y no fue reelegido. Pero cada día que pasa aumenta el reconocimiento a un filósofo moral y político que no dudó en llevar al centro de la sociedad y el

1 Mill, John Stuart, Autobiografía, Trad. Prólogo y notas de Carlos Mellizo, Madrid, Alianza Editorial, 1986.

2 En estos momentos estoy terminando la introducción a una edición en castellano que incluye por primera vez el texto que Mill leyó en el Parlamento defendiendo el derecho de las mujeres a ser ciudadanas. También incluye su intervención en una comisión parlamentaria en que expresó con contundencia su rechazo a la regulación estatal de la prostitución de mujeres. Saldrá en la editorial Almud, Ediciones de Castilla-La Mancha. 
parlamento sus elaborados principios ${ }^{3}$. John Stuart Mill, el autor de Sobre la libertad y El sometimiento de las mujeres.

\section{El principio de participación y la competencia de las élites}

John Stuart Mill, destinado a defender y propagar la teoría democrática expuesta por su padre en On Goverment, fue evolucionando de dicha concepción de la democracia como protección, a la democracia como desarrollo, como camino hacia un ideal elevado de ser humano ${ }^{4}$. Su posición se verá atravesada por la tensión recurrente entre el decisivo papel que concede al principio participativo y el no menos crucial que otorga a la competencia de los mejores, no tanto los expertos desde un punto de vista instrumental sino los que considera la élite intelectual y moral. En general los estudiosos no se han puesto de acuerdo y hasta cierto punto han utilizado a Mill como arma arrojadiza entre teorías elitistas y participativas de la democracia. Pero desde la influyente obra de Dennis F. Thompson y el giro interpretativo que imprimieron en la década de los ochenta autores como John C. Rees, Fred Berger, John Gray y Gail Tulloch los sucesivos estudios están reevaluando y rescatando aspectos menos debatidos de su obra y lo hacen a la luz de los nuevos temas, preocupaciones y desarrollos de la filosofía política en las dos últimas décadas ${ }^{5}$.

La defensa milleana de la participación de los ciudadanos en las instituciones políticas implica un argumento educativo y se basa en su concepción del ser humano y los fines de la vida. Estos fines pueden condensarse en el desarrollo de la individualidad y la ciudadanía, dos caras de la misma moneda en su filosofía política ${ }^{6}$. La participación política es importante porque desa-

3 Una valoración muy reciente de su actuación parlamentaria en relación a su filosofía política es la de Thompson, Dennis F., «Mill in Parliament: When Should a Philosopher compromise? En Urbinati, N. y A. Zakaras (eds.), J. S. Mill's Political Thought. A Bicentennial Reassessment, Cambridge, Cambridge University Press, 2007. Un tratamiento de carácter más histórico es el de B. L. Kinzer, P. Robson y J. M. Robson, A Moralist In and Out of Parliamnet: Mill at Westminster 1865-8, Toronto, University of Toronto Press, 1992.

${ }^{4}$ Es la terminología más utilizada por los estudiosos. Un breve y buen análisis de las diferencias entre las teorías democráticas de los Mill se encuentra en Krouse, Richard W., «Two Concepts of Democratic Representation: James and John Stuart Mill» en The Journal of Politics, vol. 44, 1982, pp. 509-537. También en Macpherson, C. B., La democracia liberal y su época, Madrid, Alianza Editorial, 1981.

5 El giro de la década de los ochenta queda recogido en castellano en de Miguel, Ana, Cómo leer a John Stuart Mill, Madrid, Júcar, 1994. Una muestra excelente de las más recientes aproximaciones se haya en los capítulos de la obra editada por Urbinati, Nadia y Alex Zakaras (eds.), J. S. Mill's Political Thought. A Bicentennial Reassessment, Cambridge, Cambridge University Press, 2007.

${ }^{6}$ Remitimos al muy sugerente trabajo de Alex Zakaras, «John Stuart Mill, Individuality and Participatoy Democracy», en Urbinati y Zakaras (eds.), op. cit., pp. 200-221. 
rrolla un carácter activo, básico para el desenvolvimiento de la individualidad y también porque rechaza la individualidad individualista y sitúa en un primer plano los sentimientos sociales de los individuos. Es decir, se eleva la competencia instrumental y moral de los ciudadanos.

En primer lugar, la participación política de los ciudadanos desarrolla todas las facultades humanas, no sólo las intelectuales, su carácter activo, su capacidad de autonomía personal. Para Mill, existe una suerte de «incompatibilidad natural» entre el estado de sujeción a la voluntad de otro u otros y el desarrollo de las cualidades propias del autodominio y la proyección de la individualidad. La persona, la clase que no disfruta de la opción de participar activamente en la elaboración del destino propio y el de la colectividad, difícilmente puede acceder a desarrollar cualidades como la confianza en sí misma, la disciplina y el afán de superación personal.

Para los hombres que no son a su vez ciudadanos, el gobierno aparece con el mismo carácter de fatalidad que la naturaleza o la providencia. Al no formar parte del mismo y no poder modificar sus decisiones - a no ser implorando, como a los dioses - su carácter se vuelve abúlico o pasivo, resignado en su sentido negativo. Para Mill: «El efecto fortificante que produce la libertad no alcanza su máximo sino cuando gozamos, desde luego, o en perspectiva, de la posesión de privilegios no inferiores a los de nadie» ${ }^{7}$. Uno de estos privilegios es el de elegir o poder ser elegido a realizar las tareas propias de los ciudadanos en los gobiernos representativos.

En segundo lugar la participación política desarrolla los sentimientos sociales y solidarios de los hombres, su percepción del bien común o interés general. Mill nos invita a imaginar una sociedad en que los hombres tienen un carácter activo, pero no pueden participar en la vida pública y política. En este caso la energía humana se dedicará única y exclusivamente a conseguir el bienestar físico y material, tal vez económico. Tendríamos entonces al maximizador de beneficios que pasa por ser el prototipo de hombre del utilitarismo clásico, pero que desde luego no es el ideal de hombre milleano. Es cierto que Mill afirma en ocasiones que este estado social «materialista» es positivo - un carácter activo siempre es mejor que el carácter pasivo-, pero lo es porque prepara las condiciones sociales para que surjan en la colectividad, intereses más elevados, de índole intelectual y moral. Es un peldaño en una suerte de escala del desarrollo de las necesidades humanas. Sin embargo esta situación no debe perpetuarse porque el interés del individuo $-\mathrm{y}$ el de la familia, añade - aparecen como rivales al del resto de la comunidad. Los individuos se socializan en la idea de que su interés no sólo es distinto sino opuesto al de los demás. Si esta condición formase parte de la naturaleza humana Mill no dudaría en engrosar las filas de los teóricos de la democracia

7 Mill, J. S., Del gobierno representativo, Madrid, Tecnos, traducción de Marta C. de Iturbe, 1985 , p. 42. 
como protección. Y nada más: «si tal fuera el estado universal y el único posible de las cosas, las aspiraciones más elevadas del moralista y del legislador se limitarían a hacer de la masa de la comunidad un rebaño de ovejas paciendo tranquilamente unas al lado de las otras» ${ }^{8}$.

Pero el hombre no es una oveja, ni siquiera una oveja maximizadora de utilidades. Si ha llegado o llegara a serlo, cosa que tampoco descarta por la «empantanada mediocridad en que se encuentra la opinión pública», será debido a la influencia de la educación y el conjunto de las instituciones sobre el carácter humano. Influencia que a su juicio invierte la realidad de que el hombre «forma parte de la comunidad, y el interés público es también el suyo». De ahí la centralidad de fortalecer la participación política de los ciudadanos. La participación transforma al individuo en ciudadano. Al entrar en estos cargos el ser humano «se ve llamado a considerar intereses que no son los suyos, a consultar, enfrente de pretensiones contradictorias, otras reglas que sus inclinaciones particulares; a llevar necesariamente a la práctica principios y máximas cuya razón se funda en el bien general». ${ }^{9}$

\section{El principio de excelencia: Las élites milleanas}

«No es útil, sino perjudicial que la Constitución proclame a la ignorancia y a la ciencia con iguales títulos a gobernar el país» ${ }^{10}$. Con esta sentencia Mill expresa claramente la tensión entre dos principios clave de la democracia, el principio igualitario que afirma que todos los hombres valen lo mismo y el meritocrático que matiza que no todo lo que hacen puede valer igual. No todo proyecto de vida es igual de valioso o al menos no lo es para la comunidad humana. Contra todo relativismo, la democracia como desarrollo fomenta la participación política porque abraza la idea del ser humano como proyecto que expresa su reforma del utilitarismo benthamita «mejor ser un Sócrates insatisfecho que un necio satisfecho» ${ }^{11}$.

Lo cierto es que para el utilitarismo perfeccionista la excelencia humana existe y se encarna en hombres y mujeres concretos, las llamadas élites. Estas élites ni son económicas ni son hereditarias. Sus cualidades reposan en su mérito, su esfuerzo y su coraje y son de carácter intelectual y moral. Las élites tienen un papel importante en el progreso social y una de las obsesiones de

8 Mill, J. S., op. cit., Del Gobierno Representativo, p. 43.

9 Mill, J. S., op. cit., p. 113.

10 Mill, J. S., op. cit., p. 111.

11 Mill, J. S., El Utilitarismo, Madrid, Alianza Editorial, 1984, p. 51. Recomendamos la magnífica introducción realizada por una de las mejores intérpretes de Mill, la profesora Esperanza Guisán. También sobre la relación entre el utilitarismo y los derechos humanos el reciente libro de Álvarez Gálvez, Íñigo, Utilitarismo y derechos humanos. La propuesta de J. S. Mill, Madrid, Plaza y Valdés, 2009. 
Mill es conseguir atraerles a la participación activa, a la vida pública. Uno de los peligros importantes a los que se enfrenta la democracia es la creciente mediocridad de la opinión pública y los representantes ${ }^{12}$. Lo que difícilmente podía suceder en la democracia clásica, que un Pericles pasase desapercibido, es la norma en la civilización moderna. Mill se hace eco de la opinión ya extendida en su tiempo de que cada vez es más difícil que quienes sólo poseen talento y reputación accedan al parlamento y cita la experiencia americana para afirmar que los mejores están excluidos de la representación nacional y las funciones públicas como si sufrieran las consecuencias de una «incapacidad legal». «Es un hecho reconocido que en la democracia americana, constituida sobre este erróneo modelo, los individuos más eminentes de la comunidad, exceptuando aquéllos que están dispuestos al sacrificio de sus opiniones y manera de pensar, viniendo a ser los órganos serviles de sus inferiores en saber, no optan al Congreso ni a las legislaturas de los Estados; tan cierto es que no tienen ninguna probabilidad de ser elegidos» ${ }^{13}$.

La búsqueda de mecanismos políticos para atraer y asegurar un lugar de influencia a los mejores le parece una cuestión central para que la democracia sea un motor de progreso, un camino hacia la utopía. El problema radica a veces en las medidas que propone e incluso en el lenguaje que utiliza, hablando aquí y allá de los espíritus superiores y los espíritus inferiores, lenguaje y medidas - como la del voto plural en que llegó a proponer conceder más de un voto a los mejores ${ }^{14}$ - que hieren la sensibilidad democrática actual. Sin embargo, para Mill la cuestión es demasiado decisiva y mantiene sin dudarlo que hay privilegios que no son opuestos al espíritu de la democracia, al contrario, «Un privilegio accesible a todos los que justifiquen reunir las condiciones en que descansa, en teoría y en principio no lastima ningún sentimiento de justicia» ${ }^{15}$.

La democracia no puede valorar igual al corrupto que al honrado y al héroe, tiene que alentar claramente un modelo de ciudadanía. El problema que se le plantea al autor de Sobre la libertad es cómo conciliar esta demanda con el desarrollo de la individualidad. La democracia tiene que rehuir el paternalismo, elegir libremente es el único camino para desarrollar la individualidad. John Stuart Mill ha pasado a la historia de las ideas por sus argumentos para rechazar de forma radical la figura del tutor excelente. Vivir es elegir y es mejor equivocarse que una vida colmada de aciertos, pero sometida a tutela ${ }^{16}$.

12 Este es uno de los temas recurrentes de Sobre la libertad.

13 Mill, J. S., op. cit., Del gobierno representativo, p. 91. Resuena en esta cita el eco de Alexis de Tocqueville y su influyente Democracia en América.

14 Cfr. Kern, Paul B., «Universal Suffrage without Democracy: Thomas Hare and John Stuart Mill», en Review of Politics, vol. 34, n. ${ }^{\circ} 3,1972$, pp. 306-323, p. 316.

15 Mill, J. S., op. cit., Del gobierno representativo, p. 109.

${ }^{16}$ He desarrollado en diversos escritos la relación tan estrecha que existe entre Sobre la libertad y El sometimiento de las mujeres. Puede afirmarse que Mill comprende el valor de la 
Pensamos que la solución a este problema se encuentra en la teoría política democrática y en la extensión de los principios democráticos a la economía y a la familia. Nuestro objetivo en los apartados siguientes es mostrar que la filosofía política de Mill piensa las reformas institucionales de acuerdo con el fin de desarrollar simultáneamente un carácter activo y virtuoso. El problema, como bien señalara Semmel, es el de cómo sin renunciar a fomentar la libertad y la autodeterminación es posible persuadir al ser humano para que abrace la virtud ${ }^{17}$. La respuesta está en buena medida en el proyecto inacabado de sentar las bases de una nueva ciencia social, la etología o ciencia que estudia la formación del carácter humano. Este proyecto fue expuesto por Mill en el capítulo sexto de su influyente obra El sistema de Lógica y es sin duda una de las claves que explican la unidad y la coherencia de su evolución intelectual y de su filosofía política ${ }^{18}$.

\section{La deliberación como mediación entre el principio de participación $y$ el principio de excelencia ${ }^{19}$}

La deliberación, la constitución de los parlamentos deliberativos y la formación de una sólida opinión pública aparecen como la solución práctica a cómo conjugar el principio participativo con el principio de excelencia. Esto explica la importancia que Mill concede a la constitución de parlamentos deliberativos a escala local, parlamentos que se caracterizan por la interacción entre el pueblo y las élites. La participación política de los ciudadanos en instituciones locales tiene la gran ventaja de fomentar el contacto personal, intelectual y moral entre las élites y el pueblo llano. Para que esta interacción sea

libertad al comprender lo que la sociedad les hacía a las mujeres de su tiempo. De hecho mantiene que Sobre la libertad fue escrita junto con Harriett Taylor Mill. Cfr. de Miguel, Ana, «El feminismo en clave utilitarista ilustrada: John Stuart Mill y Harriett Taylor Mill», en C. Amorós y A. de Miguel (eds.), Teoría feminista. De la Ilustración a la Globalización, Madrid, Minerva, 2005.

17 Semmel, Bernard, John Stuart Mill and the Pursuit of Virtue, New Haven, Yale University Press, 1984, pp. 83 y ss.

18 Acaba de aparecer en castellano una nueva edición de este libro, Mill, J. S., La lógica de las Ciencias Morales, Madrid, CSIC, Colección Clásicos del pensamiento, 2010. Recomendamos la excelente introducción hecha por Francisco Álvarez con el título «La vigencia intelectual de John Stuart Mill». También del mismo autor «John Stuart Mill: la etología que nunca se escribió», en R. Aramayo, J. Muguerza y A. Valdecantos, El individuo y la historia, Barcelona, Paidós, 1995. Con un planteamiento similar Feuer, Lewis S. (1976), «John Stuart Mill as a Sociologist; the Unwritten Ethology», en Robson, John M. y M. Laine (eds.), Papers of The Century Conference, Toronto, University Press, 1976.

19 En torno a los enfoques actuales sobre la democracia deliberativa, el libro de Gutman, Amy y Dennis F. Thompson, Why Deliberative Democracy, New Jersey, Princeton University, 2004, supone un buen estado de la cuestión y aporta una magnífica bibliografía. También, claro está, los conocidos ensayos de autores como Jurgen Habermas y Carlos S. Nino. 
posible — aunque no sólo por esta razón - Mill va a defender la centralización de la administración local a través de parlamentos ${ }^{20}$.

De acuerdo con el principio de competencia de los expertos el poder ejecutivo sí necesita dividirse según los conocimientos que necesitan las diferentes ramas de la administración, pero no sucede así con los parlamentos, cuyas tareas son de inspección y control del ejecutivo por un lado y de debate y promoción del interés público por otro. En la esfera política la división del trabajo no significa repartirlo en proporciones insignificantes, sino diferenciar y separar las operaciones que sólo pueden ser bien ejecutadas por una sola persona de las que requieren la reunión de varias. Si se forman tales parlamentos locales se podrá atraer al mundo de la política a algunas de las personas más eminentes de la colectividad. Para Mill, es difícil que una persona de cultura e intereses elevados se sienta atraída por la perspectiva de formar parte de una «comisión de desagüe» o un «consejo de empedrado», pero si es más probable que encuentre interés en acudir a dicho parlamento local si es un parlamento deliberativo.

La interacción entre los miembros de la comunidad es positiva para las dos partes, las dos tienen algo que aprender de la otra y, sin embargo, rara vez se da espontáneamente en las sociedades. Mill deposita una gran confianza en la influencia que sobre el común de los mortales puede tener la combinación de la participación política más el ejemplo moral de la élite. Para subrayar la relevancia de esta combinación utiliza la metáfora de la participación política como escuela de ciudadanía. Si la participación es una auténtica escuela, una buena escuela se caracteriza tanto por la presencia de alumnos como de profesores. Sería entonces un grave error prescindir del profesor, de la élite intelectual y moral. Lo mismo afirma cuando considera los límites, tanto por defecto como por exceso, de la intervención del gobierno en la educación y desarrollo de la ciudadanía. El gobierno que quiere hacerlo todo, es como un maestro que sustituye a sus alumnos y contesta a todo por ellos: es muy popular, pero a costa de no enseñar nada. Ahora bien, su opuesto, un gobierno que se abstiene de hacer todo lo que pueden realizar por su cuenta los ciudadanos, tampoco enseña nada, es a su vez como una escuela sin maestro.

Las reformas institucionales milleanas están siempre pensadas bajo el principio de que «detrás de un gobierno libre tiene que haber un pueblo libre». El futuro de la democracia está ligado al modelo de ser humano que forjen sus instituciones y la participación y la deliberación son mecanismos para fortalecer el compromiso de los ciudadanos con el buen gobierno, con el interés común.

El fortalecimiento de la responsabilidad individual es también la razón de su sorprendente oposición al voto secreto, una de las reivindicaciones más queridas de sus compañeros radicales. Si con esta medida los radicales pre-

20 Mill defiende la democracia participativa a diferentes niveles no sólo en el local, pero de acuerdo con los objetivos de este artículo basta esta muestra para exponer los argumentos a favor de la deliberación. 
tendían salvaguardar la libertad de la elección, lo que pretendía Mill era salvaguardar la responsabilidad y coherencia del ciudadano. El sufragio es ante todo un deber y comporta una responsabilidad pública; es también un derecho, pero de muy diferente índole a otros derechos como puede ser el de propiedad. Podemos vender o regalar nuestra casa pero no podemos o no debemos hacer lo mismo con nuestro voto, nuestro derecho sobre él no es absoluto: «si el sufragio es un derecho, si pertenece al votante por él mismo ¿cómo censurarle porque lo venda o lo emplee para congraciarse por algún motivo interesado con determinada persona?... ( )... Se trata estrictamente de un deber: el elector está obligado a votar según su opinión más acertada y concienzuda del bien público. Quien se haya forjado otra idea del sufragio no es digno de poseerlo: su espíritu está pervertido o ineducado. En vez de abrir su corazón a un doble patriotismo y a la obligación del deber público el sufragio despierta y nutre en semejante individuo la disposición a servirse de una función pública según su interés, su placer o su capricho; sentimientos en menor escala, pero iguales a los que guían la conducta de un déspota o un opresor» ${ }^{21}$.

Lo que distingue el derecho al voto de otros derechos es que éste concede poder y por tanto queda vinculado a la responsabilidad pública, de un modo similar a lo que sucede cuando un ciudadano ocupa un puesto en la administración. Es su derecho ocupar este puesto, pero eso no significa que pueda utilizarlo de acuerdo con sus intereses personales. En este sentido es en el que afirmamos que Mill concebía el voto, por mucho que hoy no se haga así, como un acto de auténtica participación política ${ }^{22}$. Y se opone al voto secreto porque lleva a la consecuencia, no suficientemente meditada por sus defensores, de que el votante piensa que puede disponer del mismo a su antojo. Y no es así, debe tener en cuenta las necesidades y deseos de los demás, el bien común o interés general. También es cierto que Mill considera que esta «máxima de moralidad pública» puede infringirse excepcionalmente para evitar el mal mayor de la coacción por parte de las clases dominantes. Sin embargo, a su juicio, esto, que fue un problema real en el pasado, no es la norma en la sociedad de su tiempo. Tendencias como el continuo ascenso del poder de las clases media y proletariado apuntan a que el problema del voto no vaya a ser, en el futuro, la coacción, sino el ejercicio irresponsable del mismo.

Allan Ryan se ha preguntado si la creencia de Mill en los aspectos benéficos del voto público está bien fundada, y ha planteado una objeción común a otros comentaristas: el filósofo está pidiendo un coraje excesivo al ciudadano medio, ciudadano en el que generalmente no deposita grandes expectativas ${ }^{23}$.

21 Mill, J. S., op. cit., Del Gobierno representativo, p. 123.

22 A este respecto (y otros) hay que leer la reconocida obra de Nadia Urbinati que explora las raíces griegas de la teoría política de Mill. Cfr. Urbinati, N., Mill on Democracy: From the Athenian Polis to Representative Government, Chicago, University of Chicago Press, 2002.

23 Ryan, Allan, John Stuart Mill, London, Routledge \& Kegan Paul, 1974, pp. 212-213. 
La crítica de Ryan es más que razonable, pero no se puede olvidar que para Mill el triunfo efectivo de la democracia, frente a su mera implantación legal, está relacionado con el progresivo desarrollo de la razón y el coraje de los ciudadanos. Si éstos actúan de forma irracional o cobarde acabarán perdiendo la democracia, o disfrutando una democracia «bajo mínimos», con voto secreto o sin él. Por otro lado, Mill realiza una reflexión interesante sobre el sentido de la publicidad del voto y que tal vez contribuye a restar ingenuidad al planteamiento anterior y considerar el lado más pragmático y estratega del filósofo. En primer lugar, plantea la posibilidad de aprovechar la motivación que todo ser humano alberga de ser estimado por sus semejantes. Se puede confiar en que la publicidad arrancará un voto «virtuoso» al elector porque: «La gente está ansiosa de enseñar el mejor lado de su carácter, incluso a aquéllos que no son mejores que ellos mismos». Esta cita entra de lleno en una de esas paradojas de la condición humana que permiten confiar racionalmente en un mundo mejor. El filósofo utilitarista está planteando una curiosa identificación artificial de intereses a través de una sanción positiva - la búsqueda de aprobación - pero, en última instancia, subyace su firme creencia de que la búsqueda del propio interés no recibirá nunca la alabanza moral de los demás, ni siquiera de los especialistas en actuar en provecho propio. Frente a la sección mandevilliana del utilitarismo — «vicios privados, virtudes públicas»- la búsqueda del propio interés nunca podrá asociarse definitivamente con la moralidad. Será una de esas asociaciones morales posibles dada la plasticidad de la condición humana, pero, tarde o temprano desechadas por la razón, tal y como argumenta en El utilitarismo.

La publicidad y la transparencia son dos elementos clave del debate social y político democrático: «Supongamos que el legislador tratase una cuestión que concerniese especialmente a las mujeres, como el saber si éstas podrían optar a los grados universitarios, o si las ligeras penas infligidas a los miserables que golpean diariamente a sus mujeres poniéndolas casi a las puertas de la muerte, no deberían ser sustituidas con otras más eficaces (...) ¿es que a las esposas, a las hijas, no les asistiría el derecho de saber si su marido o su padre votaba en pro o en contra del candidato que sostuviera esas proposiciones?» ${ }^{24}$. La exposición clara y pública de los intereses siniestros, en este caso los intereses de género, irracionaliza y deslegitima automáticamente dichos intereses. Mill, en el fondo optimista como buen reformador social, no cree descabellado esperar que los votantes se abstengan de proclamar públicamente su interés en perpetuar situaciones injustas a su favor ${ }^{25}$.

Es cierto que algunas de las propuestas concretas de John Stuart Mill no logran pasar el test de la historia, pero si tenemos en cuenta su recurso al mé-

24 Mill, J. S., op. cit., Del gobierno representativo, p. 127.

25 Y sin embargo, no fue así cuando Mill defendió el derecho al voto femenino en el parlamento. Los señores diputados se atrevieron a mostrar claramente su interés en seguir conservando el poder sobre las mujeres. 
todo de ensayo y error para adoptar medidas concretas en la vida política, podemos pensar que no le costaría ir descartando sus propias medidas si finalmente no sirven al fin propuesto. $\mathrm{Y}$ esto es lo que nos ha interesado argumentar, los fines con que diseña las instituciones políticas. En este caso, el desarrollo de la responsabilidad de los ciudadanos, la idea de que la democracia es, sin duda, exigente, pero merece la pena el esfuerzo.

\section{Democracia en la esfera económica: el cooperativismo}

En una carta redactada en 1869, en el tramo final de su vida, Mill especifica que la igualdad de las mujeres y la producción en cooperativas son los dos grandes cambios que regenerarán la sociedad ${ }^{26}$. En el siguiente apartado trataremos sus reflexiones sobre la igualdad sexual como escuela de igualdad política, ahora veremos en qué se basan sus expectativas sobre los cambios que proporcionarán las cooperativas.

Para Mill la sociedad de clases es un estado transitorio en la evolución de la humanidad. El que exista una clase de trabajadores y otra de no trabajadores es transitorio, porque en un estado moral avanzado y como también sostendría Marx «todos deben trabajar». Desde este presupuesto y con la colaboración directa de Harriet Taylor, Mill dedica un capítulo de sus Principios de Economía Política a examinar la situación futura de la clase trabajadora ${ }^{27}$.

A punto de salir a la imprenta el Manifiesto Comunista y en una Europa en que el sufragio masculino también está vetado a los obreros, Mill se enfrenta a la corriente de opinión que propugnaba la dependencia o protección como el mejor destino posible para la clase trabajadora. Esta variación decimonónica del despotismo Ilustrado mantiene que la suerte de los trabajadores «debe regularse para ellos, no por ellos.» Este enfoque es, reflexiona Mill, el mismo que se aplica a las mujeres. El ideal de las relaciones entre las clases y entre los géneros es el patriarcalismo tradicional, una relación de «tutela afectuosa por un lado y de deferencia respetuosa y agradecida por el otro». Siguiendo con la analogía tanto a proletarios como mujeres «no debe exigírseles otra cosa que el trabajo de cada día y que sean morales y religiosos» ${ }^{28}$.

Mill plantea dos objeciones a esta postura. En primer lugar, se basa en una visión idealizada del pasado, visión que si algo tiene en común con otras

${ }_{26}$ Mill, J. S., «Carta a Parker Godwin», enero de 1869, citado en Duncan, Graeme, Marx and Mill. Two Views of Social Conflict and Social Harmony, Cambridge, Cambridge University Press, 1973, p. 247.

27 Esta obra fue publicada en 1848 y tal y como sucedió con El sistema de la Lógica y otras de sus obras se convirtieron en un auténtico e inesperado éxito editorial.

28 Mill, J. S., Principios de Economía Política, México, Fondo de Cultura Económica, Traducción de Teodoro Ortiz, 1985, p. 645. 
añoranzas es el hecho de que no ha existido nunca. La clase que ha detentado el poder nunca se ha caracterizado, a no ser de forma excepcional, por ejercer una tutela afectuosa sobre los trabajadores. Al contrario. El problema radica en que este enfoque concita adhesiones porque, si bien el ideal de vida social descrito no ha existido nunca, sí existen los sentimientos a los que alude. Mill encuentra que hay algo naturalmente atractivo en la idea de una sociedad basada en los afectos personales y la abnegación desinteresada, frente a una sociedad basada en los intereses económicos, el atractivo de lo que a veces denomina la «moral caballeresca.» Para el autor de Sobre la libertad los avances de la sociedad actual han dejada trasnochado este ideal de regulación de las relaciones humanas: «Ningún hombre ni mujer que posee los medios de vida o que puede ganárselos con su trabajo, precisa más protección de la que la ley podría y debería darles» ${ }^{29}$. Frente a otras interpretaciones, esta tajante afirmación pone de relieve que cuando apela al desarrollo de los sentimientos sociales y solidarios no lo hace de una forma paternalista o conservadora. Los sentimientos morales que busca desarrollar se basan en la simpatía $y$ no se traducen en beneficencia sino en justicia.

En segundo lugar, aunque esta teoría resultase haber sido cierta en el pasado, las clases trabajadoras «no se sujetarán nunca más al sistema de gobierno patriarcal». Para Mill, son varias las influencias que han contribuido a despertar el derecho a la autonomía de la clase obrera. El acceso a la instrucción, simplemente a leer y escribir, a la prensa y las distintas ideologías políticas, su socialización en las fábricas, la perspectiva del derecho al voto ha hecho que las clases trabajadoras hayan tomado sus intereses en sus propias manos y que este avance sea irreversible. Desde este momento de «autoconciencia» el futuro de la clase obrera está en sus propias manos. Sencillamente, no van a consentir que nadie gobierne en su lugar, y el progreso de la sociedad depende en parte de su constitución en hombres activos y con sentimientos sociales desarrollados ${ }^{30}$.

El acceso de los obreros a la educación y a la militancia sindical tendrá como consecuencia importante una distribución más justa de la producción. Pero no sólo eso. Al filósofo inglés, en coherencia con su concepción de la individualidad, le resulta inconcebible que gente educada en valores tales como la independencia estén dispuestos a vivir toda su vida como trabajadores asa-

29 Mill, J. S., op. cit., Principios de Economía Politica, p. 647.

30 También existe un (a veces agrio) debate sobre si Mill era más liberal que socialista. Algunos autores han querido interpretar el socialismo o cooperativismo de Mill como una mera muestra de realismo político ante el ascenso del proletariado, aunque sin dejar de señalar, como hace Macpherson, que también «se sentía moralmente asqueado por la vida que se veían obligados a llevar los obreros». Cfr. Macpherson, C. B. (1981), La democracia liberal y su época, Madrid, Alianza Editorial, p. 61. Otros estudian el por qué de su encrucijada. Aquí remitimos al reciente trabajo de Baum, Bruce, «J. S. Mill and Liberal Socialism», en Urbaniti, N. y A. Zakaras (eds.), op. cit., pp. 98-123. 
lariados. Seguramente, a medida que aumente la educación de los obreros, se desarrollará una tendencia a constituirse en sus propios patronos, productores independientes. Esta independencia es un paso previo en el desarrollo de la autonomía de la clase trabajadora, pero no es un ideal en sí mismo. El principio de la independencia es sustituido por uno superior, ya que no es el aislamiento, sino la asociación, el principio que debe regular todas las relaciones humanas: «Pero si lo que se desea es que se desarrollen el espíritu público, los sentimientos generosos, la justicia y la igualdad, la escuela en que se fomentan todas estas cualidades es la de la asociación y no la del aislamiento. La finalidad del progreso no debe ser tan sólo la de situar a los seres humanos en condiciones de que no tengan que depender los unos de los otros, sino permitirles trabajar los unos con o para los otros, unidos por relaciones que no entrañen subordinación» ${ }^{31}$.

En los Principios de Economía Politica se explica con detalle el funcionamiento y el éxito de numerosas experiencias cooperativas. Y, aunque su progresiva implantación le parece una tendencia empírica y real de su tiempo, sostiene que debe ser apoyada y reforzada, pues, como se ha podido apreciar en el texto anterior, la cooperación económica fomenta y desarrolla el mismo tipo de carácter que la participación política: «el espíritu público, los sentimientos generosos, la justicia y la igualdad». La propuesta es clara, la democracia también tiene que extenderse a la economía. Esto no implica que desaparezca la libertad de mercado, pero sí extender el área en que los trabajadores o los ciudadanos puedan controlar importantes decisiones que afectan a toda la comunidad, tanto como pueden afectarla las decisiones políticas.

\section{Democracia en la esfera privada: una escuela de igualdad}

John Stuart Mill comienza El sometimiento de las mujeres, subrayando que su objetivo es fundamentar una opinión que ha mantenido desde su juventud, y en la que no ha hecho sino afianzarse con el progreso de su experiencia y reflexión ${ }^{32}$. Esta opinión es la siguiente: «que el principio que regula las relaciones sociales vigentes entre los dos sexos (la subordinación legal de un

31 Mill, J. S., op. cit., Principios de Economía Política, p. 653.

32 The Subjection of Women se ha traducido de casi todas las maneras posibles: La esclavitud femenina, La sujeción de las mujeres (la más difundida) y, recientemente también con el título de El sometimiento de las mujeres. Publicada en 1869 llegó a convertirse, en palabras del historiador Richard J. Evans en «La biblia de las feministas». Hasta hace dos décadas muchas de las monografías sobre Mill ni la mencionan. Hoy es difícil escribir con fundamento sobre su filosofía sin señalar la centralidad de su feminismo. La estudiosa María Morales ha recopilado algunos de los mejores y más influyentes escritos sobre esta obra. Cfr. Morales, M. (ed.), Mill's The Subjection of Women, Maryland, Rowman\&Littelfield Publishers, 2005. 
sexo al otro) es injusto por sí mismo y que, en nuestros tiempos, es uno de los mayores obstáculos que se oponen al desarrollo humano» ${ }^{33}$. Las instituciones patriarcales, todas las relacionadas de un modo u otro con la opresión de las mujeres, son un hecho aislado en el mundo moderno. El carácter distintivo de la modernidad es que la vida de los hombres ya no está indisolublemente ligada a su nacimiento. Pero esa modernidad no roza siquiera a las mujeres y se constituyen en el único caso - con la excepción de la realeza y una vez abolida la esclavitud - en que leyes e instituciones deciden a priori, y en virtud de la «fatalidad de nacimiento», a qué han de dedicar su vida ${ }^{34}$. Las leyes no sólo prohíben explícitamente su acceso a la educación superior, a la mayor parte de los trabajos no proletarios y a cualquier tipo de actividad política, también reglamentan su régimen de casi total sumisión a la otra parte contratante del casi único contrato que se les permite firmar: el matrimonial. Además de con el principio de libertad, el patriarcado - el sistema de relaciones que institucionaliza y legitima la dominación de un género-sexo sobre el otro- está en contradicción con el otro gran principio en que se basan las instituciones modernas, el de justicia. El progreso humano, en el que no hace falta decir Mill creía firmemente, se puede medir por el hecho de que ya no se reconoce el derecho del fuerte a oprimir al débil. La ley de la fuerza ha dejado paso a la ley de la justicia, según la cual, todos tienen los mismos derechos. A partir de esta igualdad social originaria, sólo lo que el hombre hace, su esfuerzo y su mérito, pueden llevarle a ocupar legítimamente posiciones de poder $\mathrm{u}$ autoridad, tanto en la vida pública como en la que se considera privada.

Libertad e igualdad son los dos principios que presiden las instituciones modernas y en los que se funda el progreso de la humanidad. Ahora bien, el patriarcado no sólo viola flagrantemente ambos principios sino que imposibilita que éstos se cumplan efectivamente en el resto de las instituciones sociales. Para Mill, la solución a este problema aparece con la claridad y distinción propios de una idea cartesiana para todos aquéllos que no estén cegados por la costumbre y el prejuicio: hasta que la relación humana «más universal y que todo lo penetra», como es la relación entre hombres y mujeres, no deje de basarse en la injusticia, es difícil, por no decir imposible, que el resto de las relaciones sociales sean justas y libres.

33 Mill, J. S., El sometimiento de las mujeres (1869), Madrid, Edaf, Traducción de Alejandro Pareja, 2005, p. 71. La filósofa Amelia Valcárcel desarrolla con contundencia la tesis de que la gran innovación moral de nuestros días proviene de la libertad de las mujeres. Cfr. Valcárcel, A., Feminismo en un mundo global, Madrid, Cátedra, 2008.

34 En palabras de Celia Amorós y en homenaje a la gran Simone de Beauvoir «las mujeres son un proyecto proyectado». Cfr. Amorós, C., La gran diferencia y sus pequeñas consecuencias para la vida de las mujeres, Madrid, Cátedra, 2005. 


\section{El argumento de la competencia moral o la familia como escuela de igualdad}

Este argumento sobre la relación entre el feminismo y el progreso humano nos remite a la filosofía política milleana. Como hemos visto en los apartados anteriores el establecimiento de una auténtica democracia exige un notable cambio del carácter humano, el desarrollo de los sentimientos sociales y solidarios, frente al egoísmo e insolidaridad actuales. En este sentido Mill va a realizar una severa crítica de la familia patriarcal. Por un lado destruye los sentimientos sociales de las mujeres: lógicamente al cerrarles la vía de la participación en la vida pública, la virtud de las mujeres se reduce sólo al cuidado abnegado de su núcleo familiar y tal vez se extiende a la vida social a través de la caridad. Para Mill caridad no es sinónimo de justicia, y además colocar los intereses familiares por encima de los de la sociedad no contribuye precisamente a la solidaridad humana.

En su ya clásica obra Política Sexual Kate Millett, una de las fundadoras del feminismo radical, sostiene que al igual que Engels definió la desigualdad sexual como el modelo de la jerarquía basada en la clase y la propiedad, Mill descubrió en esta complicada relación de subordinación «las raíces psicológicas de otros tipos de opresión» ${ }^{35}$. Éstas son las palabras del filósofo inglés a las que se refiere: «Todas las tendencias egoístas, la egolatría, el personalismo injusto, que existen en la humanidad, tienen su origen y su raíz, y se nutren principalmente, de la constitución actual de las relaciones entre los hombres y las mujeres» ${ }^{36}$.

El poder que de forma totalmente arbitraria, es decir, independiente del mérito y el esfuerzo personal, concede el patriarcado a una mitad de la humanidad sobre la otra, es el germen de la desigualdad injusta y los sentimientos antisociales que caracterizan la sociedad de su tiempo. El proceso de interiorización de la prepotencia y la desigualdad que caracteriza a los varones comienza en la infancia. El problema que agudamente señala Mill es el de cuál pueda ser la influencia del hecho de la subordinación y falta de derechos de las mujeres en el proceso de socialización. Cualquier joven varón, por el simple hecho de serlo, se sabe inmediatamente superior en derechos a todas las personas del sexo contrario, incluso a aquellas mujeres que le son manifiestamente superiores en facultades y resultados. Y de la superioridad de derechos se deriva el derecho a mandar y ser obedecido, el derecho a opinar y tomar decisiones que en última instancia no se pueden contradecir. Así, si personas sin ningún mérito ni esfuerzo especial detentan el poder directamente y por razones estrictamente biológicas, ¿qué efectos puede tener esto en el carácter

35 Millett, Kate, Política Sexual, México, Aguilar, 1969, p. 139. Se refiere a la muy conocida obra de Friedrich Engels, El origen de la familia, la propiedad privada y el Estado, publicada en 1884 y todo un hito en la articulación de la «cuestión femenina» en el marxismo.

36 Mill, J. S., op. cit., El sometimiento de las mujeres, p. 213. 
humano?: «¿Podemos imaginar que todo esto no pervierte toda la manera de vivir el hombre, como individuo y como ser social?» ${ }^{37}$.

La igualdad de los sexos beneficia a la sociedad en su conjunto, es una condición necesaria para el desarrollo de la competencia moral de la humanidad. Si la familia patriarcal es una institución clave en la perversión de principios morales básicos, con su transformación es posible prever el fin del desarrollo, o cuando menos del fortalecimiento, de los instintos antisociales y antidemocráticos. Y es que, reflexiona Mill, por mucho que las instituciones políticas modernas puedan hacer por transformar el carácter humano, su influencia no es superior a la de la familia, agente socializador primordial: «En los países libres, la ciudadanía es en parte una escuela de vida social en igualdad; pero la ciudadanía no llena más que un lugar pequeño en la vida moderna, y no toca ni de cerca las costumbres diarias ni las opiniones más íntimas. La familia constituida con justicia sería la verdadera escuela de las virtudes de la libertad» ${ }^{38}$.

Pensamos que buena parte de la vitalidad que despliega hoy la obra conjunta de John Stuart Mill se debe, sin duda, a la carga de profundidad que introduce en los temas que trata su reflexión sobre las consecuencias del sometimiento de la mitad de la raza humana, las mujeres. Pero también a su continua reflexión sobre las instituciones económicas y políticas en relación al modelo de persona y de vida que decidamos promover. De ahí el interés de sus reflexiones sobre las experiencias de carácter cooperativista y muy especialmente, sobre la participación política y la democracia deliberativa como las otras vías, junto a la igualdad sexual, para forjar un carácter humano más activo, valiente y solidario. El carácter necesario para el desarrollo de la individualidad, el fin de la vida humana.

37 Mill, J. S., op. cit., El sometimiento de las mujeres, p. 88.

38 Mill, J. S., op. cit., p. 148. 